\title{
Sistem Informasi Pengolahan Data Anak dan Guru pada Yayasan Rumah Qur'an Violet Indonesia Berbasis Website
}

\author{
Nurdini Purwanti ${ }^{1}$, Intan Dwi Fatmaningtyas ${ }^{2^{\star}}$ \\ ${ }^{1}$ Manajemen Informatika; Universitas Bina Insani; Jl. Raya Siliwangi No 6 Rawa Panjang \\ Bekasi Timur 17114 Indonesia, Telp (021) 82436886 / (021) 82436 996. Fax (021) 824009 \\ 24; e-mail: nurdinipurwanti89@gmail.com \\ ${ }^{2}$ Rekayasa Perangkat Lunak; Universitas Bina Insani; Jl. Raya Siliwangi No 6 Rawa Panjang \\ Bekasi Timur 17114 Indonesia, Telp (021) 82436886 / (021) 82436 996. Fax (021) 824009 \\ 24; e-mail: intandwi@binainsani.ac.id \\ * Korespondensi: e-mail: intandwi@binainsani.ac.id
}

Diterima: 8 November 2020; Review: 12 November 2020; Disetujui: 19 November 2020;

Cara sitasi: Purwanti N, Fatmaningtyas ID. 2020. Sistem Informasi Pengolahan Data Anak dan Guru pada Yayasan Rumah Qur'an Violet Indonesia Berbasis Website. Informatics for Educators and Professionals. 5 (1): 53 - 62.

\begin{abstract}
Abstrak: Rumah Qur'an Violet Indonesia merupakan suatu yayasan yang berdiri untuk memberantas buta baca dan huruf Al-Qur'an yang memiliki beberapa cabang di pelosok Nusantara. Salah satunya yaitu Anak Sahabat Qur'an Nusantara (ASQN), ASQN memiliki data santri yang cukup banyak di berbagai pulau. Melakukan pengawasan diberbagai Nusantara sangatlah sulit dilakukan oleh pihak RQV pusat, biasaya pengolahan data hanya menggunakan berkas-berkas atau mengunakan Microsoft Excel dan biasanya disampaikan kepada kantor pusat menggunakan via email atau gedget sehingga pembuatan laporan pun sulit ditangani. Sistem tersebut menjadikan pihak kantor kualahan dalam melakukan pencarian biodata yang baru saja bergabung pada ASQN. Dari permasalahan tersebut, Yayasan RQV memerlukan adanya aplikasi pengolahan data berbasis website dengan menggunakan bahasa pemograman PHP dan menggunakan metode Waterfall. Aplikasi pengolahan data tersebut dapat digunakan dalam mengolah, mencari data santri. Dengan adanya Aplikasi pengolahan data ASQN berbasis website, kantor pusat dapat mempermudah dalam proses pencarian dan pelaporan data dengan tepat, cepat, efesien dan media informasi kepada kantor pusat lebih terarah. Sehingga Yayasan RQV Indoesia dengan adanya sistem pengolahan data ASQN ini dapat dijadikan sebagai media pendukun dalam pembuatan laporan yang diinginkan oleh pemimpin atau team managerial.
\end{abstract}

Kata kunci: Data ASQN, Pengolahan Data, Php, Sistem Informasi, Waterfall, Website

Abstract: Rumah Qur'an Violet Indonesia is a foundation that stands to eradicate illiteracy and literacy of the Al-Qur'an which has several branches in all corners of the archipelago. One of them is Anak Sahabat Qur'an Nusantara (ASQN), ASQN has quite a lot of santri data on various islands. Supervision in various archipelago is very difficult for the central RQV to do, usually data processing only uses files or uses Microsoft Excel and is usually submitted to the head office using via email or gedget so that reporting is difficult to handle. This system makes it difficult for the office to search for biodata that have just joined ASQN. From these problems, the $R Q V$ Foundation requires a website-based data processing application using the PHP programming language and using the Waterfall method. This data processing application can be used in processing, looking for data on students. With the website-based ASQN data processing application, the head office can simplify the process of searching and reporting data 
accurately, quickly, efficiently and media information to the head office is more focused. So that the Indonesian RQV Foundation, with the ASQN data processing system, can be used as a supporting medium in making reports desired by the leader or managerial team.

Keywords: Data Processing, ASQN Data, Information Systems, Php, Waterfall, Website

\section{Pendahuluan}

Perkembangan teknologi komputer saat ini mempunyai peranan yang penting dalam suatu lembaga untuk menangani berbagai macam kendala yang terjadi pada lembaga tersebut serta dapat mengelola suatu pekerjaan dengan mudah, sehingga dapat menyelesaikan pekerjaan dengan rentang waktu yang singkat. Untuk meningkatkan kualitas suatu lembaga diperlukan suatu sistem yang terkomputerisasi agar dapat melakukan pekerjaan dengan cepat dan tepat. Yayasan Rumah Qur'an Violet (RQV) Indonesia merupakan suatu lembaga pendidikan agama yang bergerak dibidang pendidikan sebagai lembaga dalam memberantas buta huruf Al-Qur'an dan menyebarkan ilmu tersebut kebeberapa plosok Indonesia. Penggunaan sistem informasi pada instansi ini adalah sistem informasi pengolahan data yang dapat menghasilkan prosedur input dan output yang dapat mempengaruhi kinerja sistem baik jangka pendek maupun jangka panjang.

Yayasan RQV Indonesia sudah menggunakan sistem yang terkomputerisasi dengan menggunakan Microsoft Excel, namun belum maksimal dalam melakukan penyimpanan data, sehingga data dapat mengalami kerusakan maupun kehilangan yang bisa saja terjadi sewaktuwaktu. Sehingga RQV Indonesia membutuhkan sistem informasi yang harus di rancang dengan semaksimal mungkin dalam menangani pengolahan data yang dapat mendukung informasi yang berkualitas dan dapat menyajikan laporan dalam bentuk pdf yang bisa diserahkan langsung pada presiden RQV Indonesia.

Sistem merupakan suatu sistem yang terdiri atas bagian-bagian atau komponen yang terpadu untuk satu tujuan. Model dasar dari bentuk sistem ini adalah adanya masukan, pengolahan, dan keluaran. Sistem dapat terbuka dan tertutup akan tetapi sistem informasi biasanya adalah sistem terbuka [1]. Informasi adalah hasil dari pengolahan data dari satu atau berbagai sumber, yang kemudian diolah, sehingga memberikan nilai, arti dan manfaat [2]. Sistem informasi merupakan suatu kombinasi teratur dari orang-orang, hardware, software, jaringan komunikasi dan sumber daya data yang mengumpulkan, mengubah, dan menyebarkan informasi dalam sebuah organsasi [3]. Pengolahan data merupakan bahan mentah untuk di olah yang hasilnya kemudian menjadi informasi. Dengan kata lain pengolahan data yaitu kumpulan data trasaksi ke sebuah pengolahan data masukan yang telah di peroleh harus diukur dan di nilai baik dan buruk, berguna atau tidak daam hubungan dan tujuan yang akan di capai [4]. Untuk melakukan desain rancangan akan menggunakan pendekatan berbasis objek diantaranya use case diagram, Use Case pada dasarnya merupakan unit fungsionalitas koheren yang diekspresikan sebagai transaksi-transaksi yang terjadi antara actor dan sistem [5]. Selanjutnya dibuatkan activity diagram, Activity Diagram dibuat untuk menggambarkan aktifitas aktor. Activity diagram salah satu jenis diagram pada UML yang dapat memodelkan proses-proses apa saja yang terjadi pada sistem [6]. Untuk rancangan data menggunakan ERD, ERD merupakan gambaran yang menghubungkan antara objek satu dengan objek yang lain dalam dunia nyata, bisa dikatakan bahwa bahan yang akan digunakan untuk membuat ERD adalah objek dari dunia nyata [7].

Hasil dari penelitian ini berupa sistem informasi pengolahan data anak dan guru berbasis website dengan menggunakan bahasa pemograman codeigniter yang merupakan salah satu Framework php yang paling powerfull saat ini karena didalamnya terdapat fitur lengkap aplikasi web, dimana fitur-fitur tersebut sudah dikemas menjadi satu dan biasanya digunakan untuk mengembangkan aplikasi web yang digunakan [8]. Serta menggunakan bahasa pemograman php yang dapat diletakkan dan dieksekusi oleh server web sebagai bagian dari suatu aplikasi web yang dapat menerima, mengolah dan menampilkan data dari sebuah website [9]. Xampp sebagai databse yang didalamnya terdapat berbgai macam aplikasi dan tool yang menyediakan paket perangkat lunak dalam sebuah paket [10][11]. Metode pengerjaannya menggunakan metode waterfall yang cara pengerjaan dari suatu sistem dilakukan secara berurutan atau secara linear. Jadi setiap tahap harus diselesaikan terlebih dahulu secara penuh sebelum diteruskan ke tahap berikutnya untuk menghindari terjadinya pengulangan tahapan [12]. 


\section{Metode Penelitian}

Metodologi penelitian ini menggunakan beberapa teknik dalam mendapatkan informasi, diantaranya 1) Observasi, teknik observasi dilakukan untuk mengumpulkan beberapa informasi pengumpulan data tentang bagaimana cara kerja pengumpulan data anak dengan mendatangi langsung tempat observasi dan melakukan pengamatan pada objek penelitian untuk menemukan masalah mengenai kelemahan dalam pengolahan data yang sedang berjalan di RQV Indonesia dan melakukan analisa dalam kelemahan yang ada serta melakukan solusi perbaikan; 2) Wawancara, proses wawancara dilakukan oleh coach Fania Vivi Hikmawati, S.E untuk memperoleh pengumpulan data dengan jalan tanya jawab sepihak yang dilakukan secara sistematis dan berdasarkan kepada tujuan penelitian. Pada tahap wawancara penanya mewawancari salah satu staff RQV Indonesia yang menguasai persoalan-persoalan yang diteliti untuk mengetahui informasi-informasi yang berupa sejarah RQV, alur pengolahan data anak dan guru secara detail; 3) Studi Pustaka, studi kepustakaan dilakukan dengan cara membaca dan mempelajari literatur dan buku-buku yang mendukung dengan topik yang dibahas dalam penyusunan laporan ini dan memanfaatkan berbagai macam pustaka yang relevan untuk memperoleh data penunjang.

Pengembangan sistem menggunakan metode air terjun (waterfall). metode waterfall sebuah pendekatan kepada perkembangan software yang sistematik dan sekuensial yang mulai pada tingkat dan kemajuan sistem pada sebuah analisis, desain, kode,. Spesifikasi kebutuhan perangkat lunak pada tahap ini perlu didokumetasikan. 1) Analisis, analisis merupakan tahap awal dimana dilakukan proses pengumpulan data, identifikasi masalah, dan analisis kebutuhan sistem hingga aktivitas pendefinisian sistem. Dalam tahap ini penulis bertujuan untuk menentukan solusi yang didapat dari aktivitas-aktivitas tersebut. Analisis sistem, meliputi gambaran umum pada yayasan, analisis sistem yang berjalan, permasalahan pada sistem, serta pemecahan masalah, biasanya penulis dapat melihat referensi berupa buku maupun aplikasi yang berada di google; 2) Desain, pembuatan model perangkat lunak. Maksud pembuatan model ini adalah untuk memperoleh pengertian yang lebih baik terhadap aliran data dan kontrol, proses-proses fungsional, tingkah laku operasi dan informasi-informasi yang terkandung di dalamnya. Terdiri dari aktivitas utama pemodelan proses, pemodelan data dan desain antarmuka. Tahapan desain sistem, akan membuat sebuah desain meliputi desain basis data, desain tampilan, dan desain sistem berdasarkan hasilanalisa pada tahap pertama; 3 ) Kode, kode merupakan tahap melakukan penulisan kode sistem menggunakan bahasa pemograman sesuai dengan spesifikasi yang telah diusulkan. Tahapan inilah yang merupakan tahapan secara nyata dalam mengerjakan suatu sistem. Kerangka pemikiran dibuat peneliti untuk menjelaskan alur logika berjalan dari sebuah penelitian. Berikut metode penelitian ini pada gambar 1.

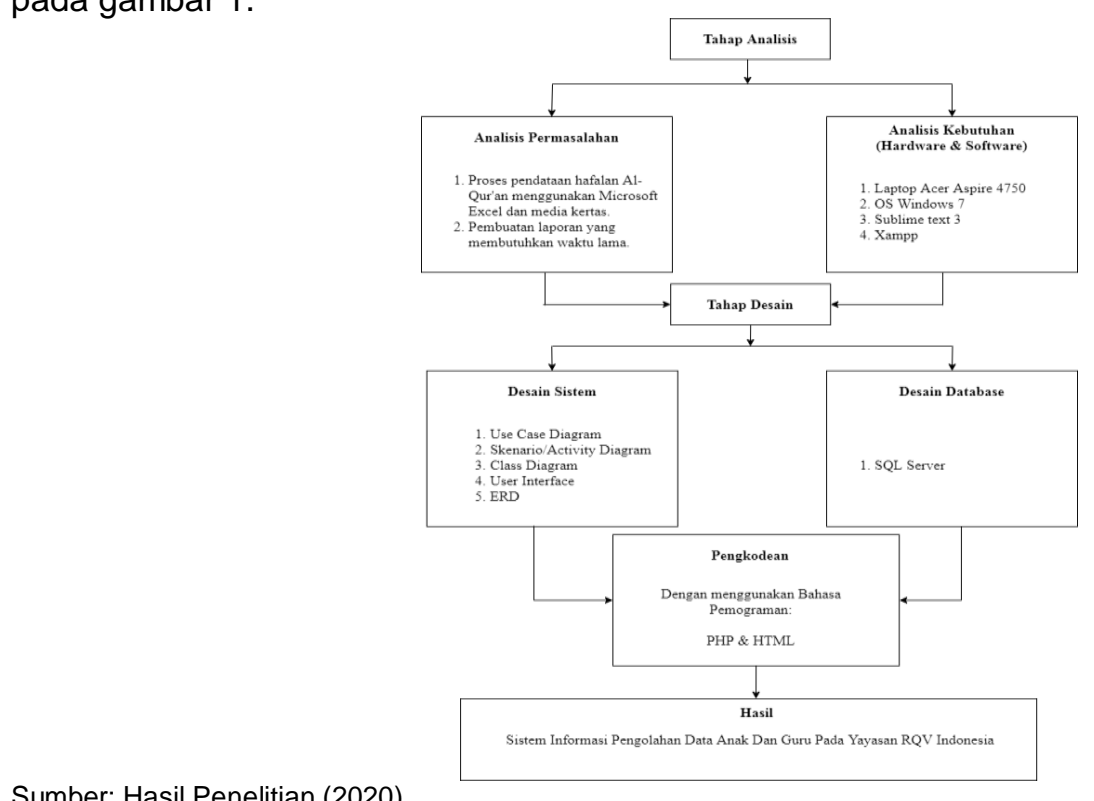

Sumber: Hasil Penelitian (2020)

Gambar 1. Metode Penelitian 


\section{Hasil dan Pembahasan}

Prose bisnis ini hanya menjelaskan tahapan proses tentang sistem berjalan pengolahan data anak dan guru yang ada pada Yayasan RQV Indoensia, adapun penjelasannya sebagai berikut 1) Coach menerima data anak santri; 2) Setelah menerima data lengkap anak santri maka coach akan melapor kepada Sekjen yang bertugas; 3) Sekjen akan menerima data dan melakukan pengecekkan pada data anak santri tersebut apakah data yang sudah dicatat lengkap dan sesuai. Jika sudah lengkap maka sekjen akan melakukan penginputan data data dengan cara pembukuan lalu akan di masukkan ke dalam Microsoft Excel; 4) Setelah melakukan penginputan data maka sekjen akan membuat laporan data anak untuk diserahkan kepada presiden RQV Indonesia; 5) Presiden RQV Indonesia menerima laporan data anak santri.

Perancangan yang dilakukan dengan merancang desain sistem dalam bentuk penggambaran yang meliputi usecase diagram yang menjelaskan kegiatan yang dilakukan oleh sistem dalam menanggapi permintaan dari pengguna sistem informasi yang akan dibuat, activity diagram yang memodelkan alur kerja sebuah proses bisnis dan urutan aktifitas pada suatu proses, database yang dirancang menggunakan Entity Relationship Diagram (ERD) yang menggambarkan hubungan antar entitas dari model konseptual suatu basis data rasional yang merupakan tampilan dari sistem infromasi pengolahan data.

\section{Usecase Diagram}

Use Case diagram merupakan sebuah kegiatan yang dilakukan oleh sistem dalam menanggapi permintaan dari pengguna sistem informasi yang akan dibuat. Pada gambar 2 berikut ini merupakan gambaran dari use case diagram pengolahan data anak pada Yayasan $\mathrm{RQV}$ Indonesia.

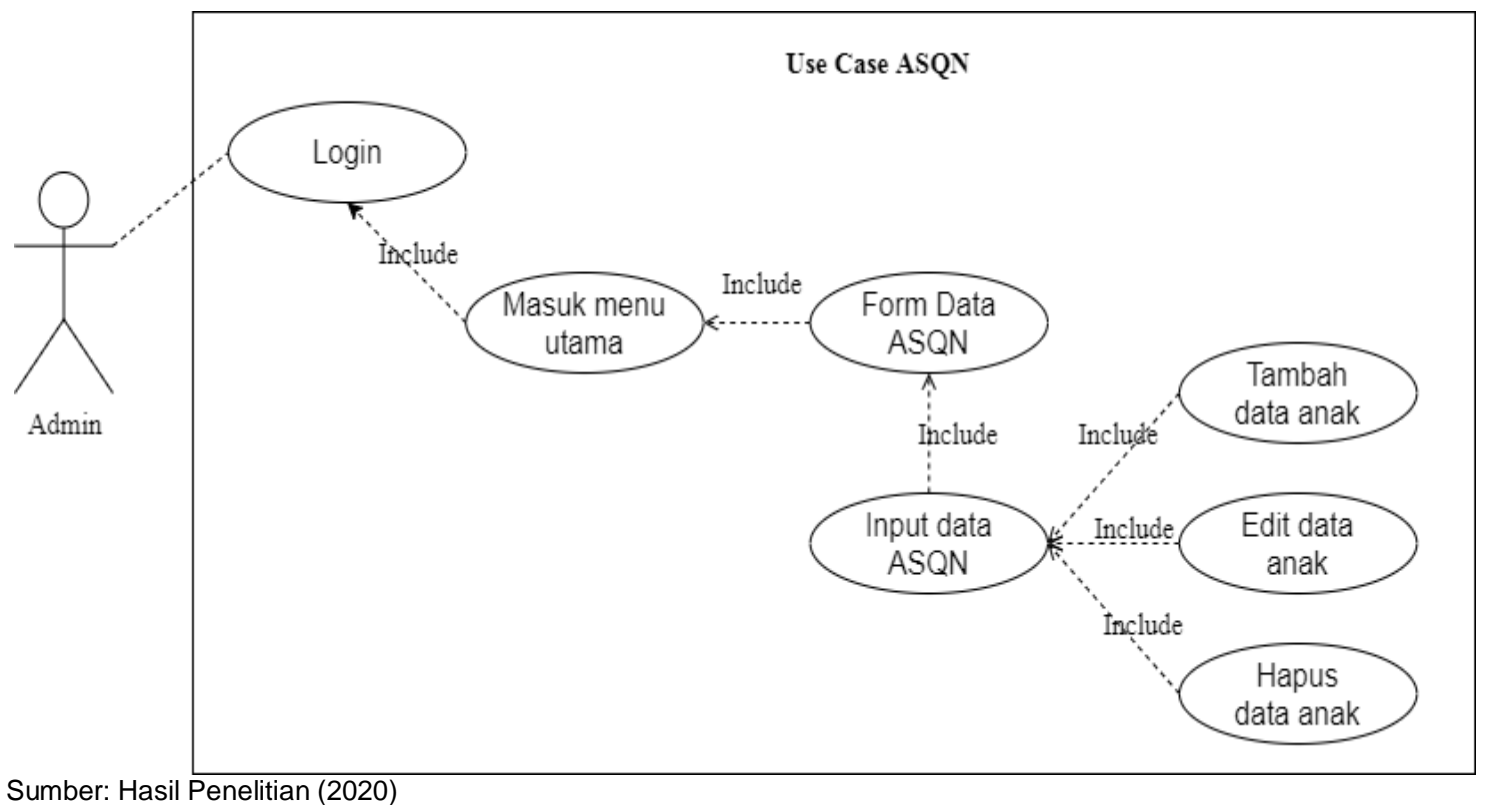

Gambar 2. Use Case Pengolahan Data Anak

Berikut merupakan scenario dari use case diagram pengolahan data:

Tabel 1. Scenario Use Case Pengolahan Data Anak

\begin{tabular}{|c|c|}
\hline Aksi Aktor & Reaksi Sistem \\
\hline & 1. Menampilka Menu Utama/Dashboard \\
\hline \multicolumn{2}{|l|}{ 2. Klik menu "Data ASQN" } \\
\hline & 3. Menampilkan form "Data ASQN" \\
\hline \multicolumn{2}{|l|}{$\begin{array}{l}\text { 4. Lakukan input data-data } \\
\text { anak/ASQN lalu klik "Simpan" }\end{array}$} \\
\hline & $\begin{array}{l}\text { 5. Menampilkan pesan "Sukses! Data ASQN Berhasil di Simpan" } \\
\text { data tersimpan ke Database dan menampilkan form data } \\
\text { ASQN }\end{array}$ \\
\hline 6. Jika akan Update klik "Edit" & \\
\hline
\end{tabular}




\begin{tabular}{|c|c|c|}
\hline & 7. & Menampilkan form edit data ASQN \\
\hline \multicolumn{3}{|c|}{$\begin{array}{l}\text { 8. Lakukan update data ASQN, lalu } \\
\text { klik "Simpan" }\end{array}$} \\
\hline & 9. & $\begin{array}{l}\text { Menampilkan pesan "Sukses! Data ASQN Berhasil di ubah" } \\
\text { dan menampilkan form data ASQN }\end{array}$ \\
\hline \multicolumn{3}{|c|}{$\begin{array}{l}\text { 10. Jika akan dihapus data, klik } \\
\text { "Hapus" }\end{array}$} \\
\hline & & $\begin{array}{l}\text { Menampilkan pesan "Apakah anda yakin ingin menghapus } \\
\text { data ini?" }\end{array}$ \\
\hline \multicolumn{3}{|r|}{ Alur Alternatif No.1 } \\
\hline \multicolumn{3}{|c|}{ 1. Jika tidak jadi menjalankan aplikasi klik "Kembali" } \\
\hline & & Alur Alternatif No.2 \\
\hline
\end{tabular}

Sumber: Hasil Penelitian (2020)

\section{Activity Diagram}

Activity diagram menggambarkan rangkaian aliran dari aktifitas, digunakan untuk mendeskripsikan aktifiyas yang dibentuk dlaam suatu operasi sehingga dapat juga digunakan untuk aktifitas lainnya .Activity Diagram berfungsi memodelkan alur kerja sebuah proses bisnis dan urutan aktifitas pada suatu proses. Activity diagram coach menjelaskan aktifitas kerja dari aktor pada saat masuk aplikasi dengan cara login terlebih dahulu, lalu aktor dapat mengolah data anak seperti edit, tambah data dan hapus data yang sudah tersedia dalam aplikasi tersebut. Berikut kegiatan activity diagram from coach yang terjadi pada Yayasan RQV Indonsia:

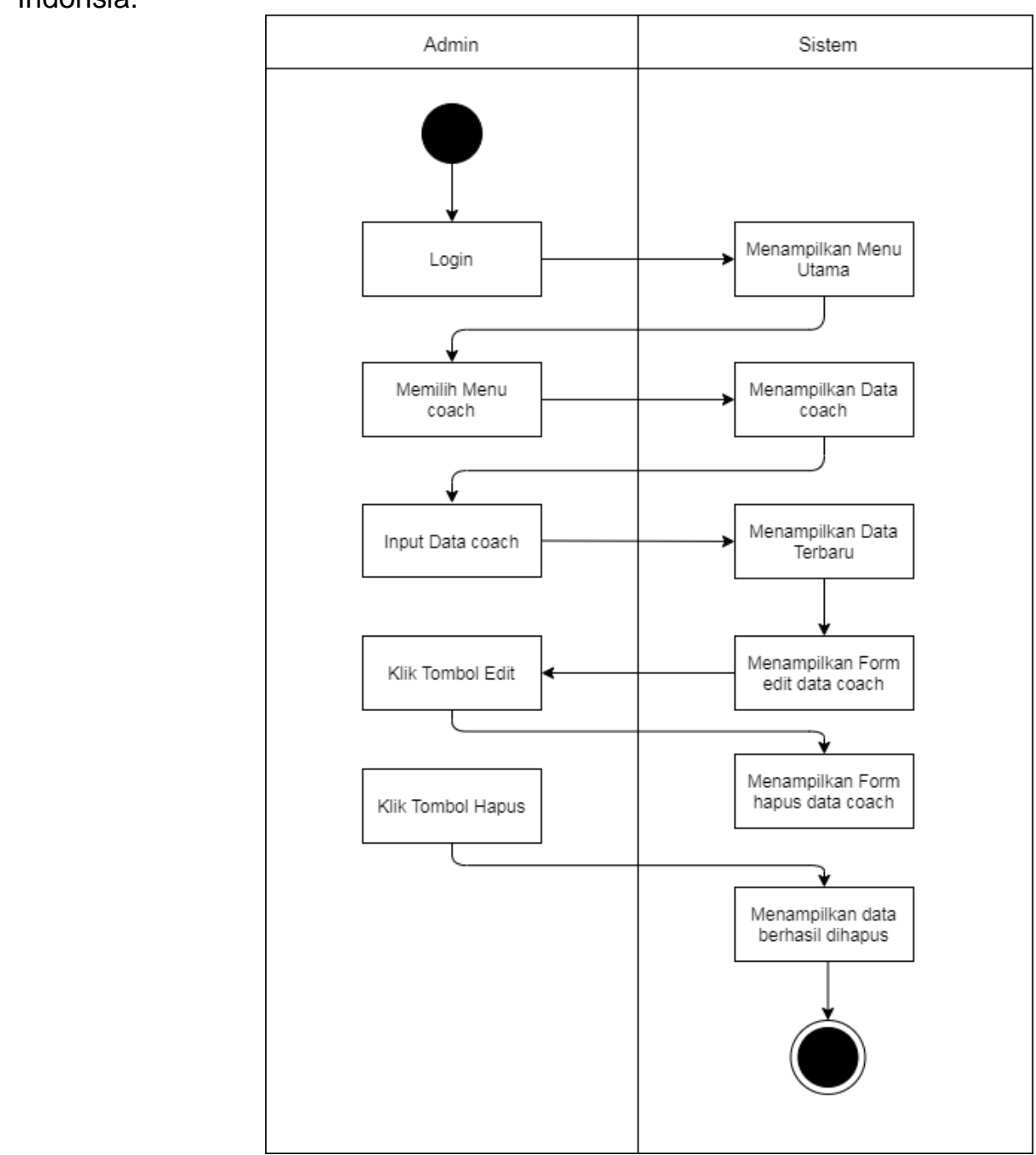


Tabel 2. Scenario Activity Diagram Coach

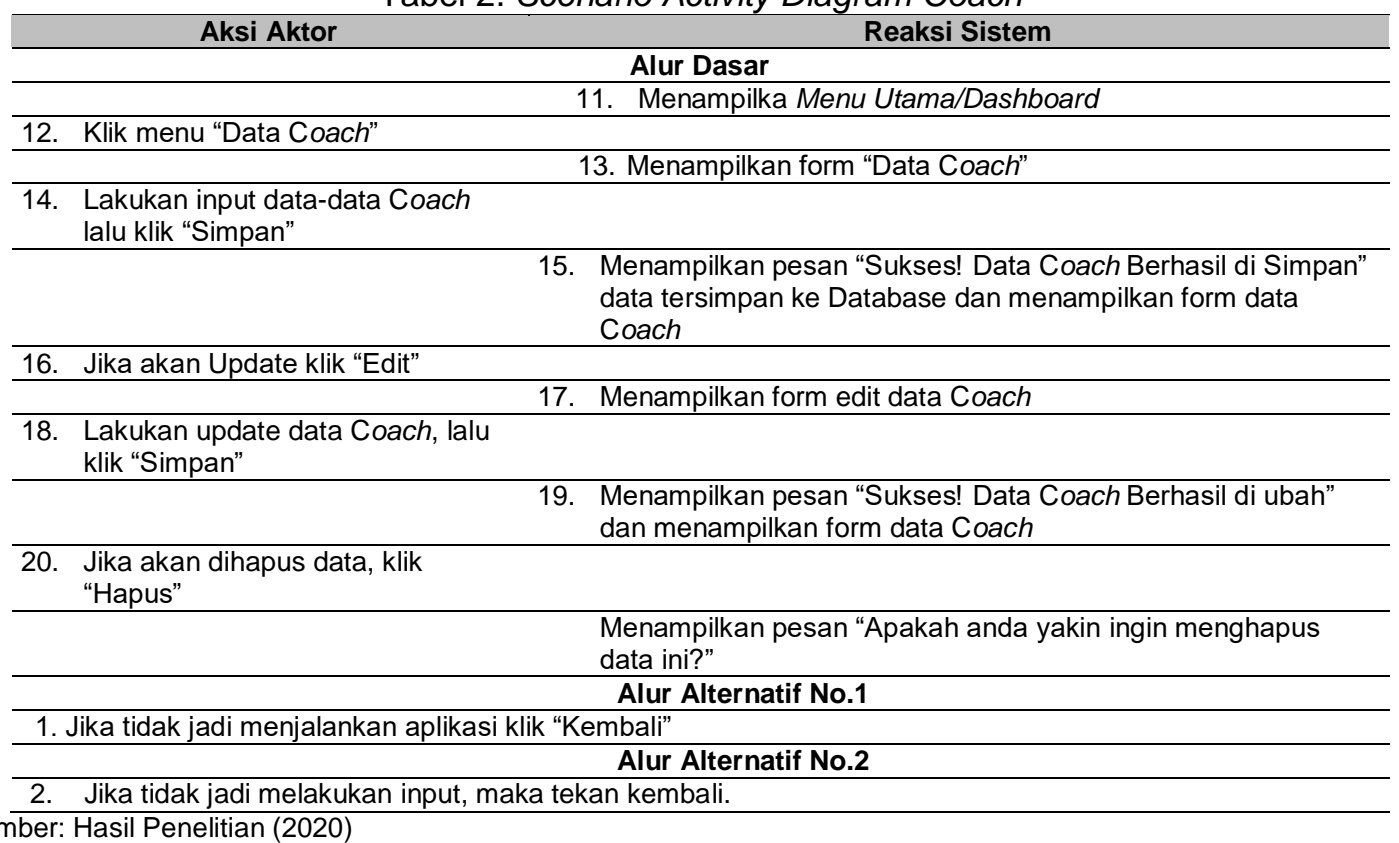

\section{Entity Relationship Diagram (ERD)}

ERD merupakan suatu diagram untuk menggambarkan desain konseptual dari model konseptual suatu basis data relasional, untuk menggambarkan ERD menggunakan beberapa notas dan simbol yang sudah terstruktur yang mempunyai beberapa tahap dalam proses pembuatannya, seperti menentukan entitas dan menentukan relasi yang akan digunakan dalam tahap pengerjannya. Aplikasi Pengolahan Data Anak dan Guru mempunyai alur yang dinyatakan dalam Entity Relationship Diagram (ERD) yang menjelaskan hubungan antara data dan basis data berdasarkan objek-objek yang sudah terstruktur dan mempunai hubungan antara relasi. Berikut merupakan relasi pada data dan basis data yang terdapat pada Yayasan $R Q V$ Indonesia yang dinyatakan dalam bentuk ERD :

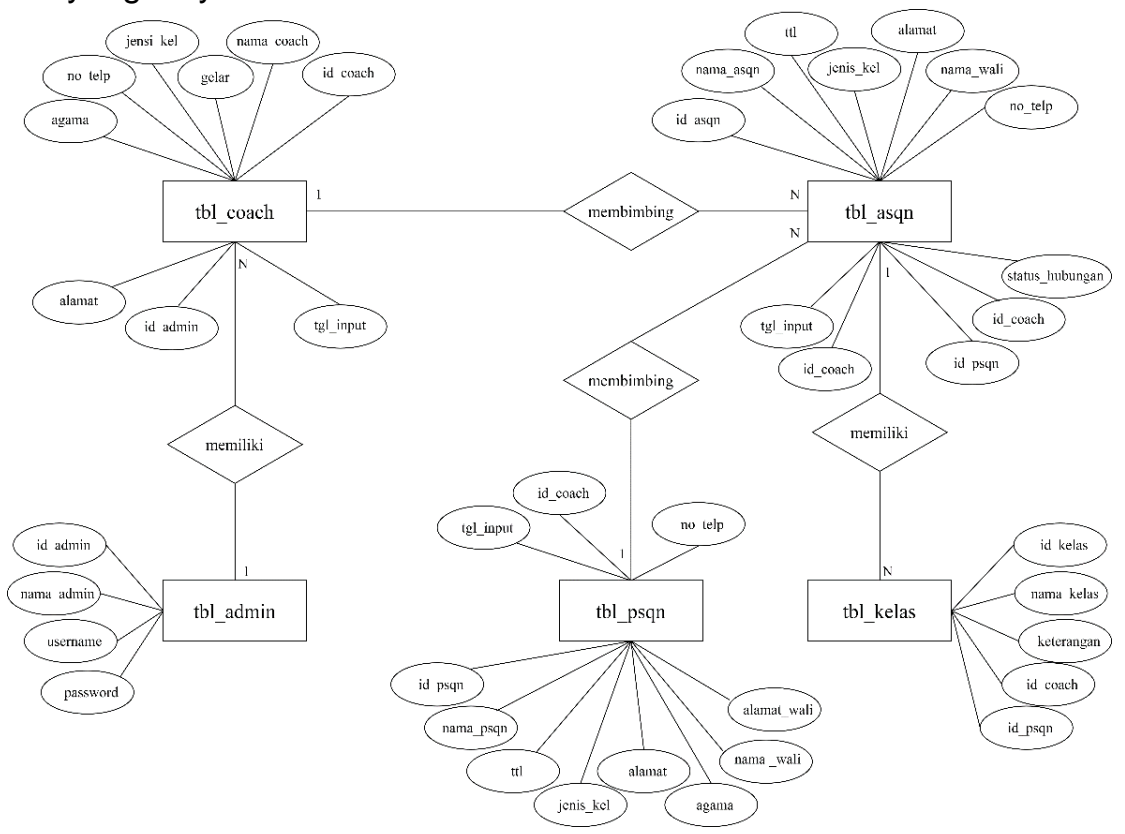

Sumber: Hasil Penelitian (2020)

Gambar 4. Entity Relationship Diagram (ERD) 


\section{Rancangan Antarmuka}

Adapun perancangan desain user interface untuk sistem informasi yang akan dibangun, akan dijelaskan pada tabel 3 .

Tabel 3. Rancangan Antar Muka

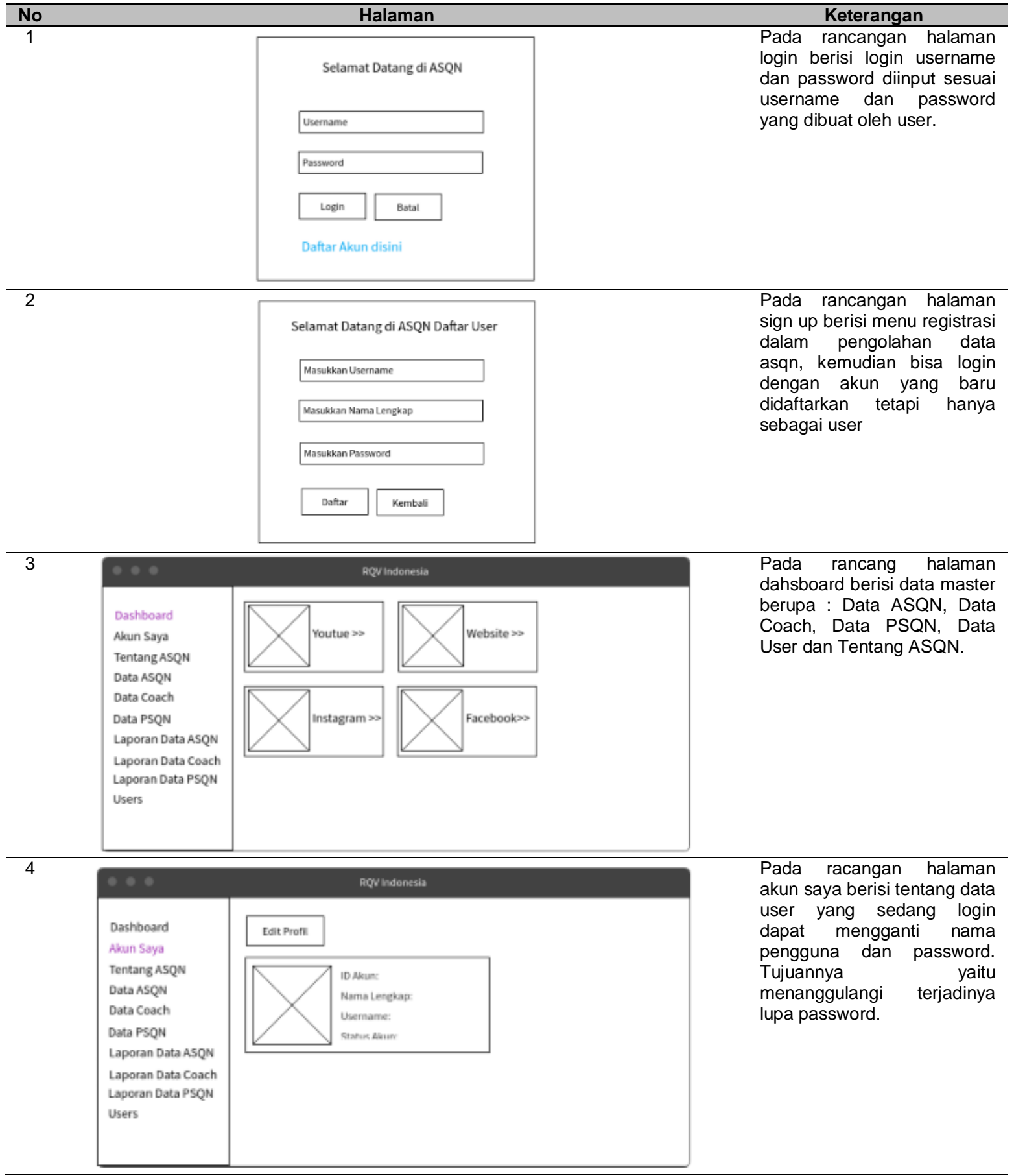




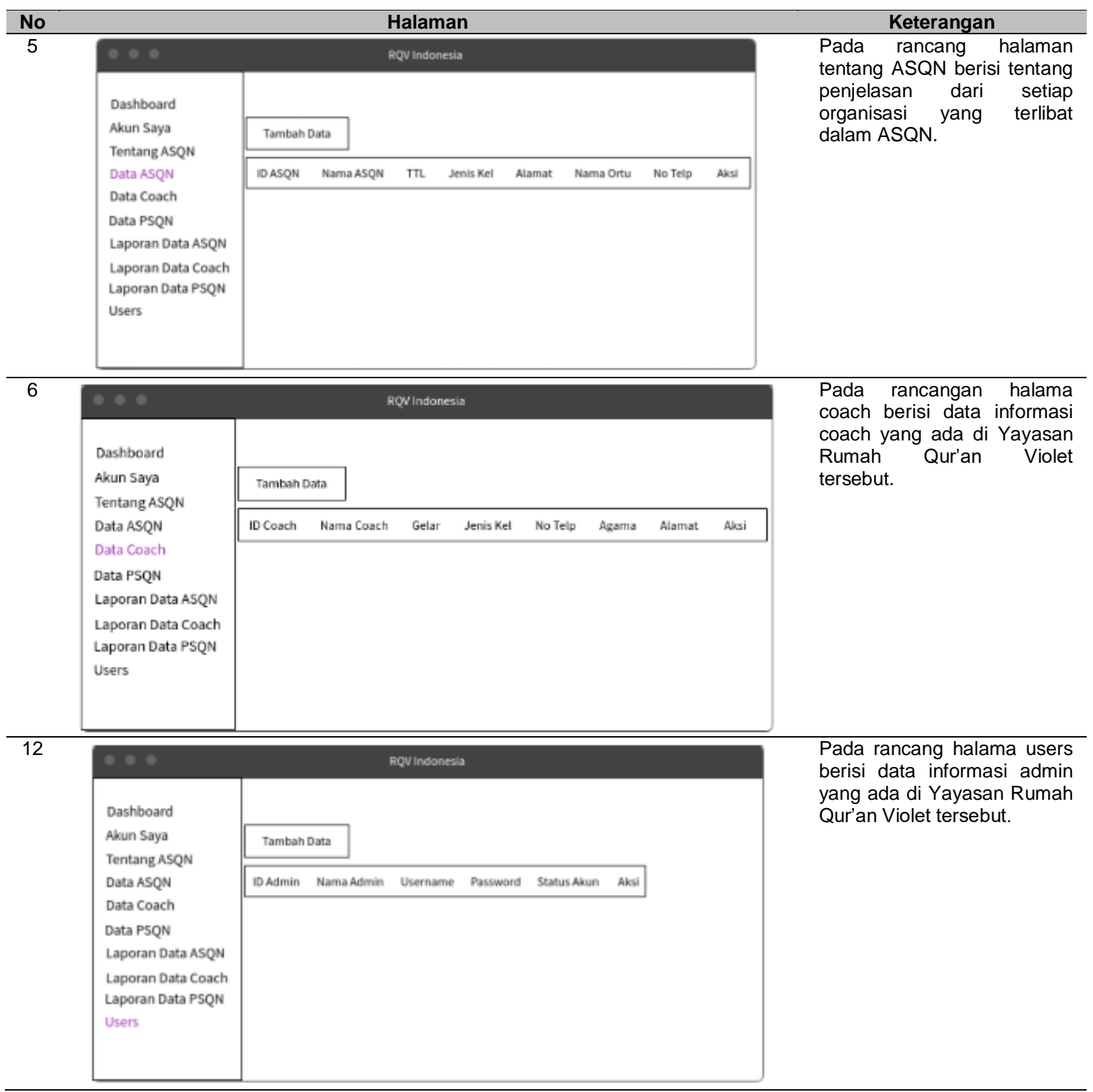

Sumber: Hasil Penelitian (2020)

\section{Implementasi Pemograman}

Pada tahap ini program yang sudah dibuat harus dilakukan implementasi agar mempunyai dampak dan tujuan yang diinginkan, pada halama ASQN berisi data informasi anak yang mengikuti kegiatan hafalan AI-Qur'an di Yayasan Rumah Qur'an Violet tersebut, gambar 5 berikut merupakan implementasi program pada tampilan halaman ASQN. 


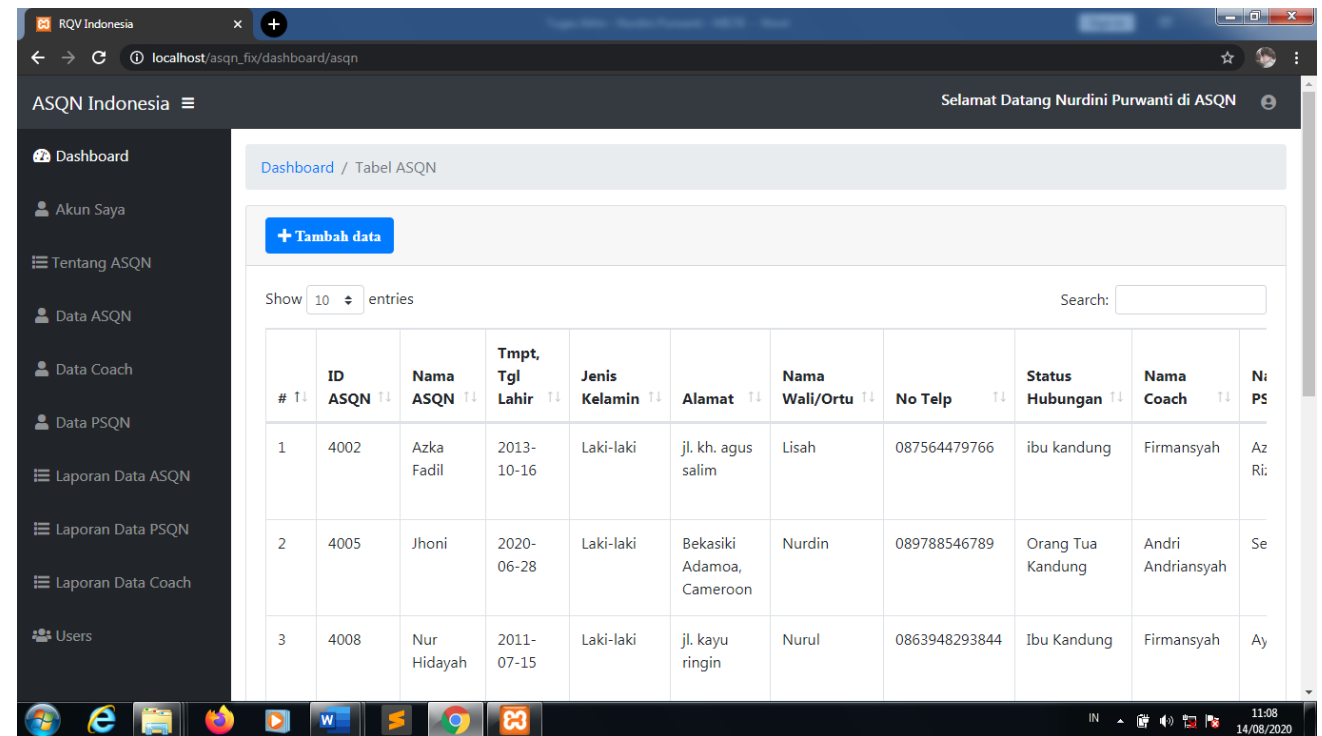

Sumber: Hasil Penelitian (2020)

\section{Gambar 5. Form ASQN}

\section{Kesimpulan}

Setelah melakukan penelitian dan mendapatkan informasi dari data-data yang ada pada Yayasan RQV Indonesia maka dapat ditarik kesimpulan yang telah dikemukakan pada bab-bab sebelumnya, antara lain: 1) Setelah adanya sistem informasi pengolahan data yang terkomputerisasi dapat mengurangi pencarian data dengan cara mencari data-data pada tumpukkan berkas; 2) Dengan adanya sistem informasi pengolahan data yang sudah terkomputerisasi dapat memperoses rangkaian manajemen pengolahan data yang dapat berjalan dengan efektif dan efesien; 3) Dengan adanya sistem informasi pengolahan data yang sudah terkomputerisasi dapat mempercepat proses pencarian data dan pembuatan laporan data yang akurat dalam bentuk pdf.

\section{Referensi}

[1] T. Sutabri, Konsep Sistem Informasi. Yogyakarta: CV. Andi Offset, 2012.

[2] I. P. Pratama, Sistem Informasi dan Implementasinya. Bandung: Informatika Banding BIObses, 2014.

[3] E. Y. Anggraeni and R. Irviani, Pengantar Sistem Informasi. Yogyakarta: CV. Andi Offset, 2017.

[4] M. Abdurahman, "Sistem Informasi Data Pegawai Berbasis Web Pada Kementerian Kelautan Dan Perikanan Kota Ternate," J. IIm. Ilk. - IImu Komput. Inform., vol. 1, no. 2, pp. 70-78, 2018.

[5] A. Nugroho, Rekayasa Perangkat Lunak Berorientasi Objek dengan Metode USDP. Yogyakarta: C.V ANDI OFFSET, 2010.

[6] B. Haqi and H. S. Setiawan, Aplikasi Absensi Dosen dengan Java dan Samrtphone sebagai Barcode Reader. Jakarta: PT. Elex Media Komputindo, 2019.

[7] E. Utami and A. D. Hartanto, Sistem Basia Data Menggunakan Microsoft SQL Server 2005. Yogyakarta: CV. Andi Offset, 2012.

[8] P. Hidayatullah and J. K. Kawistara, Pemograman Web. Bandung: Informatika Bandung BI-Obses, 2017.

[9] F. Pratiwi, S. Adrianto, and A. Arianto, "Sistem Pengolahan Data Nilai Siswa Berstandar Kurikulum 2013 Di SMP Negeri 2 Dumai," SATIN - Sains dan Teknol. Inf., vol. 4, no. 1, p. 80, 2018.

[10] Aryanto, Soal Latihan dan Jawaban Pengolahan Database MySQL Tingkat Dasar atau Pemula. Yogyakarta: CV Budi Utama, 2016. 
[11] Andi and W. Komputer, Panduan Aplikatif \& Solusi (PAS) Sistem Informasi Penjualan Online untuk Tugas Akhir. Yogyakarta: CV. Andi Offset, 2014.

[12] D. Puastuti and K. S. Abb, "Perancangan Sistem Informasi Pendataan Warga Sekolah Berbasis Web Pada Sdn 2 Pagelaran," Jpgmi, vol. 3, no. 1, pp. 26-42, 2017. 